\title{
Friction Model Identification Based on Robust Estimation of the Linear Motor
}

\author{
Hua Sun ${ }^{1.2}$, Yuehong Dai ${ }^{1, *}$ and Chuansheng Tang ${ }^{1}$ \\ ${ }^{I}$ School of Mechatronics Engineering, University of Electronic Science and Technology of China, Chengdu 611731, \\ China \\ ${ }^{2}$ School of Mechanical Engineering and Automation, Xi Hua University, Chengdu 610039, China, Chengdu 610039, \\ China
}

\begin{abstract}
Linear motor is one of the most important drive units for high-speed machining centers. Nonlinear friction is an important factor affecting the positioning accuracy of linear motor drive system. One of the most important topics for controlling linear motor is how to accurately estimate the parameters of the friction and effectively compensate it. In this paper, to solve the problem existing in traditional estimation methods that the estimation accuracy is not high enough, a novel estimation method based on robust estimation algorithm is proposed. The proposed method can effectively void the modeling error of the least squares algorithm, which will greatly improve the estimation accuracy of the nonlinear LuGre friction model. First, LuGre friction model is introduced in linear motor servo system; then, the robust estimator is design to identify the static and dynamic friction parameters in the LuGre model. Finally, simulation results verify the effectiveness of the proposed estimation scheme.
\end{abstract}

Keywords: Friction compensation, linear motors, robust estimation.

\section{INTRODUCTION}

High-speed machining center is an important device, which has significant economic value and strategic importance for defense. Linear motor is one of the most important drive units for high-speed machining centers. However, the presence of nonlinear friction has seriously impacted the position accuracy for the linear motor drive system, especially in the low-speed situation. The disadvantages of the friction in the linear motor mainly includes [1]: 1) it will produce dead-zone at zero speed, and the system has several equilibrium points, which will make the system have large static error; 2) when the value of Coulomb friction is greater than that of static friction, the introduction of integral control cannot eliminate static error, but it will make the system exhibit extreme oscillation; 3) The system will appear lowspeed crawling at low-speed and flattop phenomenon will happen when the speed value is zero.

Therefore, it is necessary to establish the precise friction model for analyzing and eliminating the friction in the system. LuGre friction model is one of the most important friction models including the stribeck effect, hysteresis, and spring-like characteristics of the stiction, as well as variant break-away force, which can accurately describe the complex friction characteristics for linear motor. However, in the LuGre friction model, the internal state $z$ cannot be measured, and there exists the coupling affects between the dynamic parameters and static parameters. In view of those factors, it is very difficult to identify the parameters in LuGre friction model. Recently, many methods have been investigated to identify the friction parameters in the LuGre model. A twostep nonlinear optimization identification method is used to estimate the parameters, which is naturally a local linear approximation method, so it has a large estimation error $[2,3]$. Genetic algorithm is employed to estimate the friction parameters $[4,5]$; however, there are some drawbacks preventing its implementation in practice, for example, many parameters should be selected, this algorithm has certain dependence on the initial populations, and it is completed to use in practice. Based on the above mentioned problems, in this paper, robust estimation method is proposed to identify the LuGre friction parameters for linear motor $[6,7]$. The estimation strategy effectively combines the advantages of linear rough differential least squares method and nonlinear least squares estimation, which is a nonlinear estimation method. Numeric simulations are performed to verify the effectiveness of the presented method.

\section{LUGRE FRICTION MODEL OF LINEAR MOTOR}

In the high-precision high-performance linear motor servo system, the nonlinear friction will make serious impact on the system static and dynamic performances, which mainly include: 1) creeping phenomenon occurs at low speed, 2) larger static steady-state poor or limit cycle oscillation $[8,9]$.

Let us consider the simplified model for a linear motor:

$m a+F_{f}=F_{e}$ 
Where, $m$ is the total effective mass, $F_{e}=k_{F} i_{q}$ is the electromagnetic force, $k_{F}$ is the electromagnetic force factor, $i_{q}$ is the q axis current, and $F_{f}$ is the nonlinear force.

LuGre friction model is the most accurate model to predict the dynamic characteristics of friction at low speeds. The LuGre friction force can be described as [1]:

$$
F_{f}=\sigma_{0} z+\sigma_{1} \dot{z}+\sigma_{2} \dot{s}
$$

$\dot{z}=\dot{s}-\frac{\sigma_{0}|\dot{s}|}{g(\dot{s})} z$

$g(\dot{\mathrm{s}})=F_{c}+\left(F_{s}-F_{c}\right) \mathrm{e}^{-\left(\mathrm{v} / \mathrm{v}_{\mathrm{s}}\right)^{2}}$

Where, $z$ describes the average deflection of the bristles modeling the contact between the interacting surfaces, $F_{c}$ denotes Coulomb friction force, $F_{s}$ denotes maximum static friction force, $\sigma_{0}$ denotes stiffness coefficient, $\sigma_{1}$ denotes the damping coefficient, $\sigma_{2}$ denotes viscous damping coefficient, $v_{s}$ denotes critical Stribeck velocity, $v$ denotes the mover velocity, and $s=\int_{0}^{t} v d t$ denotes the mover position $[10,11]$.

When the system is in steady state, then is $\dot{z}=0$, the friction can be rewritten as:

$$
F_{s s}=F_{c} \operatorname{sgn}(v)+\left(F_{s}-F_{c}\right) \mathrm{e}^{-\left(\mathrm{v} / \mathrm{v}_{\mathrm{s}}\right)^{2}} \operatorname{sgn}(v)+\sigma_{2} v
$$

The formula (5) is the typical static friction curve Stribeck curve.

We can see from formulas (2)-(4) that the LuGre friction model can be described by four static parameters $\left(F_{c}, F_{s}\right.$, $\left.\alpha, v_{s}\right)$ and two dynamic parameters $\left(\sigma_{0}, \sigma_{1}\right)$.

\section{LINESR MOTOR LUGRE FRICTION PARAME- TERS ESTIMATION METHOD}

In order to solve the problem of strong coupling in the LuGre friction model, we identify the static parameters $\left(F_{c}\right.$, $\left.F_{s}, \alpha, v_{s}\right)$ and the dynamic parameters in two steps. First, in the steady-state, the LuGre friction force is the static stribeck force. Therefore, the static parameters $\left(F_{c}, F_{s}, \alpha, v_{s}\right)$ can be identified according to formula (5). Secondly, The use of estimates instead of the actual value of the static parameters and then using the servo system lag - slip limit cycle oscillation curve to identify the dynamic parameters $\left(\sigma_{0}, \sigma_{1}\right)$. The detailed design process is as follows.

Perform experiments at constant speed for linear motor systems. Set a series of constant speed value $\left\{v_{i}\right\}_{i=1}^{N}$, and measure the corresponding friction $\left\{F_{i}\right\}_{i=1}^{N}$.
Note that constant speed means $a=0$, we can get

$F_{e}=F_{f}$

Substituting (6) into (5), we obtain that

$F_{f}=F_{c} \operatorname{sgn}(\gamma)+\left(F_{s}-F_{c}\right) \mathrm{e}^{-\left(\mathrm{v} / \mathrm{v}_{\mathrm{s}}\right)^{2}} \operatorname{sgn}(\gamma)+\sigma_{2} \gamma$

Formula (7) describes the correspondence between friction and velocity.

Define the parameter vector as follows:

$Y_{s}=\left[\hat{b}_{1}, \hat{b}_{2}\right]^{T}$

$\begin{cases}\widehat{\mathrm{b}}_{1}=\left[\widehat{\mathrm{F}}_{\mathrm{c}}^{+}, \widehat{\mathrm{F}}_{\mathrm{s}}^{+}, \hat{\alpha}^{+}, \widehat{v}_{s}^{+}\right] & v>0 \\ \widehat{\mathrm{b}}_{2}=\left[\widehat{\mathrm{F}}_{\mathrm{c}}^{-}, \widehat{\mathrm{F}}_{\mathrm{s}}^{-}, \widehat{\alpha}^{-}, \widehat{v}_{s}^{-}\right] & v<0\end{cases}$

Define the identification error:

$e\left(\mathrm{Y}_{\mathrm{s}}, v_{\mathrm{i}}\right)=\mathrm{F}_{\mathrm{i}}-F_{f}\left(\mathrm{Y}_{\mathrm{s}}, v_{\mathrm{i}}\right)$

The objective function:

$J_{s}=\sum_{\mathrm{i}=1}^{\mathrm{N}} e^{2}\left(\mathrm{Y}_{\mathrm{s}}, v_{\mathrm{i}}\right)$

When the dynamic friction parameter $\left(\sigma_{0}, \sigma_{1}\right)$ is identified, the control law of the linear motor servo system is:

$T_{(\mathrm{t})}=-k_{p}\left(\mathrm{~s}-\mathrm{s}_{\mathrm{d}}\right)-\mathrm{k}_{\mathrm{I}} \int\left(\mathrm{s}-\mathrm{s}_{\mathrm{d}}\right) d_{t}-k_{D} a$

Where, $s_{d}$ is the target location, $k_{p}, k_{I}$ and $k_{D}$ are the proportion, integral and differential coefficient respectively.

Define the identification parameter vector:

$Y_{d}=\left[\hat{\sigma}_{0}, \hat{\sigma}_{1}\right]^{T}$

Define the identification position error:

$e_{d}\left(\mathrm{Y}_{\mathrm{d}}, \mathrm{t}_{\mathrm{s}}\right)=\mathrm{S}\left(\mathrm{t}_{\mathrm{i}}\right)-\mathrm{S}_{1}\left(\mathrm{Y}_{\mathrm{d}}, \mathrm{t}_{\mathrm{i}}\right)$

Where, $S\left(t_{i}\right)$ is actual position value at $t=t_{i}, S_{l}\left(Y_{d}, t_{i}\right)$ is estimation position value at $t=t_{i}$.

Then, the linear motor servo system's Mathematical Model can be expressed as:

$m a_{l}+F_{s}=F$

$F_{f}=\hat{\sigma}_{0} z+\bar{\sigma}_{1} \dot{z}+\alpha v$

$\dot{z}=v_{l}-\frac{\sigma_{0}\left|v_{c}\right|}{g\left(v_{\mathrm{c}}\right)} z$

The objective function is selected as:

$J_{D}=C_{1} \sum_{i=1}^{N} e_{d}^{2}\left(\mathrm{Y}_{\mathrm{d}}, \mathrm{t}\right)+\mathrm{c}_{2} \max \left\{\left|e_{d}\left(\mathrm{Y}_{\mathrm{d}}, \mathrm{t}\right)\right|\right\}$ 
Table 1. Estimation results for the static friction parameters.

\begin{tabular}{|c|c|c|c|c|}
\hline Parameters & & Actual Value & Estimation Value & Estimation Error (\%) \\
\hline \multirow{2}{*}{$\mathrm{F}_{\mathrm{c}}$} & $\mathrm{S}>0$ & 28.7 & 28.4 & 1.04 \\
\hline & $\mathrm{S}<0$ & 28.5 & 28.1 & 1.40 \\
\hline \multirow{2}{*}{$\mathrm{F}_{\mathrm{S}}$} & $\mathrm{S}>0$ & 60.2 & 58.1 & 3.49 \\
\hline & $\mathrm{S}<0$ & 60.1 & 58.8 & 2.16 \\
\hline \multirow{2}{*}{$\alpha$} & $\mathrm{S}>0$ & 332.5 & 338.1 & 1.98 \\
\hline & $\mathrm{S}<0$ & 333 & 337.5 & 1.35 \\
\hline \multirow{2}{*}{ s } & $\mathrm{S}>0$ & 0.01 & 0.099 & 1 \\
\hline & $\mathrm{S}<0$ & -0.01 & -0.098 & 2 \\
\hline
\end{tabular}

Where, $c_{1}$ and $c_{2}$ are the weight coefficients. The dynamic parameters can be obtained by solving the minimum of the objective function (18).

\section{ROBUST ESTIMATION FOR LINEAR MOTOR NONLINEAR FRICTION PARAMETERS}

In the non-linear model parameters estimation, the system model must be linearized first for robust least squares estimation method. However, this will inevitably lead to the model estimation error. If we use this method to deal with gross error, it may cause incorrect gross error identification and localization. Therefore, we presented a robust estimation method to identify the friction parameters for linear motor servo system.

Suppose $L=\left(L_{1}, L_{2}, \ldots, L_{n}\right)$ is an independent observation with the different precision and the corresponding weight matrixes $P=\operatorname{diag}\left(p_{1}, p_{2}, \ldots, p_{n}\right)$.

The nonlinear observation error is:

$E=f(\hat{X})-L$

Solving the error criterion function equation (19) can be expressed as the following optimization problem:

$\sum p_{i} \rho\left(e_{i}\right)=\min$

Where, $\rho\left(e_{i}\right)$ is the optimization target function.

Let the partial derivatives of equation (19) equal to zero, that is

$\sum p_{i} \frac{\partial \rho\left(e_{i}\right)}{\partial e_{i}} \frac{\partial e_{i}}{\partial x_{i}}=0$

Let

$$
\left.\begin{array}{c}
\frac{\partial \rho\left(e_{i}\right)}{\partial e_{i}}=\Psi\left(e_{i}\right) \\
\omega_{i}=\frac{\Psi\left(e_{i}\right)}{e_{i}}
\end{array}\right\}
$$

Substituting (22) into (21), we can get

$\sum p_{i} \omega_{i} e_{i} \frac{\partial e_{i}}{\partial x_{i}}=0$

Where $\omega_{i}$ is weight factor, $\bar{P}_{i}=p_{i} \omega_{i}$ is equivalent weight.

The introduction of equivalent weight $\bar{P}_{i}$ can not only retain the advantages of least squares estimation, but also has the ability to resist gross error contamination. And the weight factor $\omega_{i}$ is used to make the equivalent weight more reasonable. The matrix form of (23) can be expressed as:

$$
\left(\frac{\partial f(X)}{\partial x_{i}}\right)^{\prime} \bar{p}\left(f(\hat{X})-L_{i}\right)=0
$$

The nonlinear function is an implicit function, so the simplex method is used in this paper to solve the above problem. The selection of function $\Psi\left(e_{i}\right)$ usually has the following two forms: 1) based on the energy minimum principle, J. Saleh derives the weight factor expression in each case; 2) IGG method proposed by Wenjiang Zhou.

$$
\Psi\left(e_{i}\right)=\left\{\begin{array}{cc}
1 \quad\left|e_{i}\right| \leq 1.5 \sigma \\
\frac{k \sigma}{\left|e_{i}\right|} & 1.5 \sigma<\left|e_{i}\right| \leq 2.5 \sigma \\
& 0 \quad\left|e_{i}\right|>2.5 \sigma
\end{array}\right.
$$

Using the robust estimation, Table $\mathbf{1}$ and $\mathbf{2}$ gives the identification results for linear motor LuGre friction model.

\section{SIMULATION RESULTS}

In this section, to illustrate the effectiveness of the proposed robust estimation, numeric simulation is conducted on linear system. The parameters of the linear motor are select- 


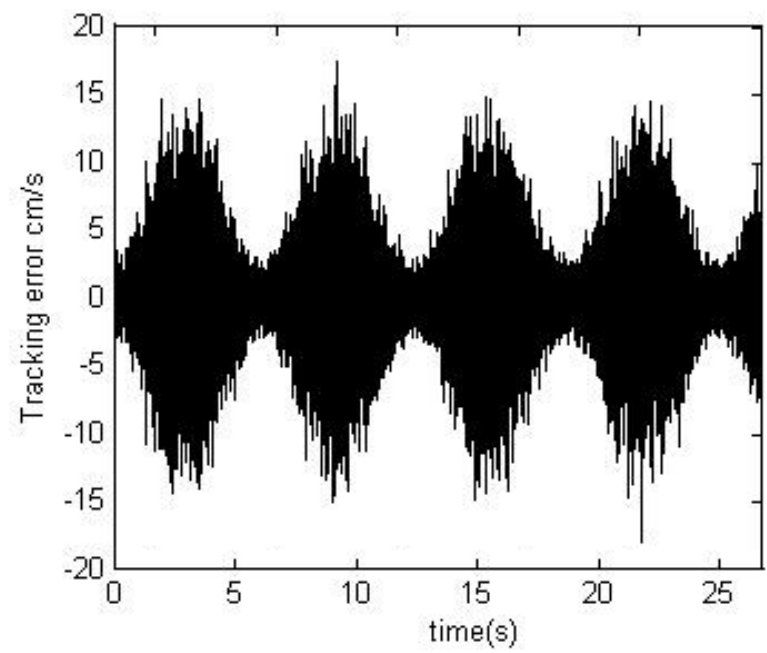

Fig. (1). The speed tracking error without robust estimation.

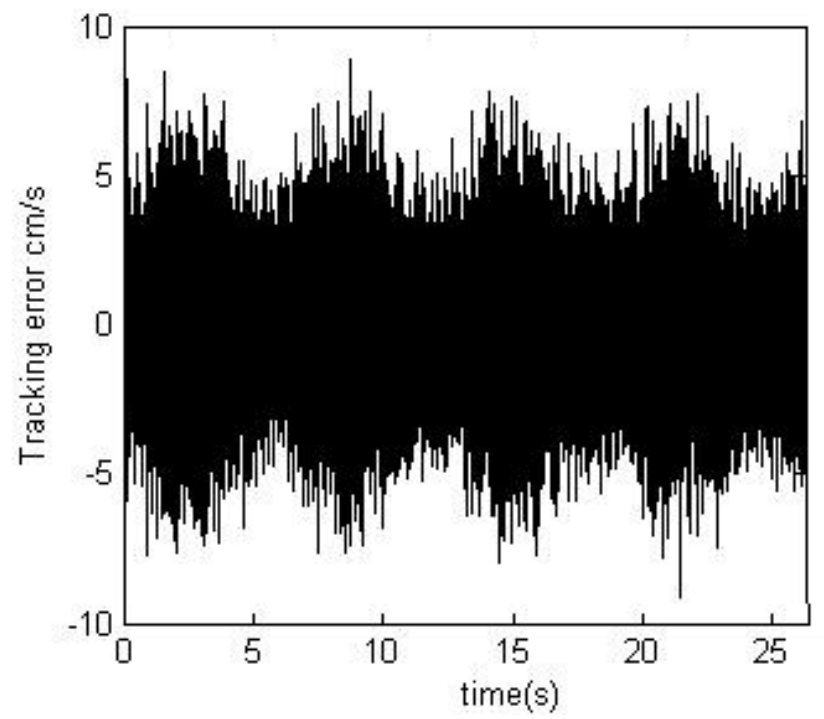

Fig. (2). The speed tracking error with robust estimation.

ed as: $m=25 \mathrm{~kg}, K_{\mathrm{F}}=25 \mathrm{~N} / \mathrm{A}$, inductance $L=18.74 \mathrm{mH}$, stator resistance $R=1.2 \Omega$. Choosing speed ideal signal $v_{d}(t)=\sin (2 \pi t)$, simulation results are shown in Fig. (1) and Fig. (2). Fig (1) shows the speed tracking error without friction parameters estimation and composition. It can be seen from Fig. (1) that the maximum speed tracking error is about $18 \mathrm{~cm} / \mathrm{s}$. using the proposed robust estimation method and friction composition, the maximum error is less than $10 \mathrm{~cm} / \mathrm{s}$, as seen in Fig. (2).

Table 2. Estimation results for the dynamic friction parameters.

\begin{tabular}{|c|c|c|c|}
\hline Parameters & Actual Value & Estimation Value & $\begin{array}{c}\text { Estimation } \\
\text { Error (\%) }\end{array}$ \\
\hline \hline$\sigma_{0}$ & $10^{5}$ & $9.79 \times 10^{4}$ & 2.1 \\
\hline$\sigma_{1}$ & 31.62 & 32.66 & 3.3 \\
\hline
\end{tabular}

\section{CONCLUSION}

Stability at low speed is an important issue for high precision linear motor servo system. The more predominant effects associated with the linear motor are nonlinear friction, which will inevitably arise as long as there is relative motion between two contacting bodies. How to identify and composite the nonlinear friction is always a topic of interest. In this paper, a robust estimation method is investigated for linear motor with LuGre friction model. Simulation results have verified that the proposed method has better speed tracking performance than that of not using the friction parameters estimation and friction composition.

\section{CONFLICT OF INTEREST}

The author confirms that this article content has no conflict of interest. 


\section{ACKNOWLEDGEMENTS}

This work is supported by the Open Research Subject of Key Laboratory (Research Base) of szjj2014-030 and State major science and technology special projects 2009ZX04001-013-04.

\section{REFERENCES}

[1] C.C. de Wit, H. Olsson, K. J. Astrom, and P. Lischinsky, "A new model for control of systems with friction", IEEE Transaction on Automation Control, vol. 40, no. 3, pp. 419-425, 1995.

[2] C.C. de Wit, and P. Lischinsky, "Adaptive friction compensation with partially known dynamic friction model", International ournal of Adaptive Control and Signal Processing, vol. 1, pp. 6580, 1997.

[3] P. Lischinsky and C.C. de Wit, "Model G. Friction compensation for an industrial hydraulic robot", IEEE Control Systems Magazine, vol. 19, no. 1, pp. 25-32, 1999.

[4] V. M. Alfaro and R. Vilanova, "Model-reference robust tuning of 2D of PI controllers for first and second-order Plus dead-time controlled processes", Journal of Process Control, vol. 22, pp. 359-374, 2013.

[5] A. Amthor, T. Hausotte, C. Ament, P. Li, and G. Jaeger, "Friction identification and compensation on nanometerscale," In:
Proceeding of IFAC World Congress, Seoul, Korea, pp. 20142019, 2008.

[6] W. Ling, "Intelligent optimization algorithms with applications (in ChinPsP, W. Ling), Bering: Tsingyuan University Press, 2001; 130-192.

[7] Y. A.-R.I. Mohamed, "Adaptive self-tuning speed control for permanent-magnet synchronous motor drive with dead time", IEEE Transactions on Energy Conversion, vol. 45, pp. 46724675, 2009.

[8] S. Lu, X. Tang, B. Song and S. Zheng, "Gpc-basedself-tuning PI controller for speed servo system of PMSLM", Asian Journal of Control, vol. 15, pp. 1325-1336, 2013.

[9] W. De-hui, "Identification for Nonlinear Dynamic System Based on SVM", Journal of System Simulation (S1004-731X), vol. 19, no. 14, pp. 3169-3171, 2007.

[10] R. Hai-na, Z. Ge-xiang and J. Wei-dong, "Selection of kernel functions and parameters for support vector machines in system identification", Journal of System Simulation (S1004-731X), vol. 18, no. 11, pp. 3204-3208, 2006.

[11] J. L. Rojo-Alvarez, M. Martinez-Ramon, M. de Prado- Cumplido, A. Artes-Rodriguez and A. R. Figueiras-Vidal. Support vector method for robust ARMA System Identification. IEEE Transactions on Signal Processing (S1053-587X), vol. 52, no. 1, pp.155164, 2004.

(C) Sun et al.; Licensee Bentham Open.

This is an open access article licensed under the terms of the Creative Commons Attribution Non-Commercial License (http://creativecommons.org/licenses/by-nc/3.0/) which permits unrestricted, non-commercial use, distribution and reproduction in any medium, provided the work is properly cited. 